\title{
Manyetik Kateter Yönlendirme Sistemleri
}

\section{Magnetic Catheter Navigation Systems}

Özge Akbülbül $1^{1 *}$, Mert Şener ${ }^{1}$, Gökhan Özdemir ${ }^{1}$, Aylin Şendemir ${ }^{2}$, Ece Bayır ${ }^{3}$, Tuncay Göksel ${ }^{4}$, Haydar Soydaner Karakuş $^{4}$, Mutlu Boztepe ${ }^{5}$, Levent Çetin ${ }^{6}$, Gökmen Atakan Türkmen ${ }^{7}$ B. Oğuz Gürses ${ }^{8}$, Aysun Baltacı ${ }^{8}$

${ }^{1}$ Ege Üniversitesi Fen Bilimleri Enstitüsü, İzmir, Türkiye

${ }^{2}$ Ege Üniversitesi, Mühendislik Fakültesi, Biyomühendislik Bölümü, İzmir, Türkiye

${ }^{3}$ Ege Üniversitesi, Merkezi Araştırma Test ve Analiz Laboratuvarı Uygulama ve Araştırma Merkezi, İzmir, Türkiye ${ }^{4}$ Ege Üniversitesi, Tıp Fakültesi, Dahili Tıp Bilimleri Bölümü, Göğüs Hastalıkları Ana Bilim Dalı, İzmir, Türkiye

${ }^{5}$ Ege Üniversitesi Mühendislik Fakültesi, Elektrik-Elektronik Mühendisliği Bölümü, İzmir, Türkiye ${ }^{6}$ İzmir Kâtip Çelebi Üniversitesi, Mühendislik ve Mimarlık Fakültesi, Mekatronik Mühendisliği Bölümü, İzmir, Türkiye

${ }^{7}$ İzmir Kâtip Çelebi Üniversitesi, Fen Bilimleri Enstitüsü Bölümü, İzmir, Türkiye ${ }^{8}$ Ege Üniversitesi, Mühendislik Fakültesi, Makina Mühendisliği Bölümü, İzmir, Türkiye

e-mail:ozgeakbulbul@gmail.com,mertsener45@gmail.com,gkhn.ozdemir.35@gmail.com, aylin.sendemir@ege.edu.tr, ece.bayir@ege.edu.tr, tuncay.goksel@ege.edu.tr, karakus70@yahoo.com.tr, mutlu.boztepe@ege.edu.tr, levent.cetin@ikc.edu.tr,gat06101995@hotmail.com,oguz.gurses@ege.edu.tr, aysun.baltaci@ege.edu.tr.

ORCID: 0000-0002-7892-6458

ORCID: 0000-0002-9343-948X

ORCID: 0000-0002-3004-2354

ORCID: 0000-0003-4886-3860

ORCID: 0000-0003-1818-6651

ORCID: 0000-0002-6089-1840

ORCID: 0000-0002-3099-9172

ORCID: 0000-0002-2750-5784

ORCID: 0000-0002-7041-0529

ORCID: 0000-0002-4845-6547

ORCID: 0000-0002-2755-3452

ORCID: 0000-0002-9049-1610

*Sorumlu Yazar/ Corresponding Author: Özge Akbülbül

Gönderim Tarihi / Received: 08.10.2020

Kabul Tarihi / Accepted: 21.02.2021

DOI: $10.34087 /$ cbusbed.804349

\section{$\ddot{O} z$}

Son 10 yılda biyopsi ve tanı işlemleri esnasında doktor vasıtasıyla manuel ve robotik olarak gerçekleştirilen endoskopi, kolonoskopi, bronkoskopi gibi işlemlerde oluşabilecek komplikasyonları en aza indirmeye yarayacak sistemlerin üzerine çalışılmaya başlanmıştır. Bu sistemlerin en önemli özelliği yönlendirilecek kateterin manyetik özelliğe sahip olması ve elektromanyetik sistemler ile kateterin temassız bir şekilde yönlendirilmesidir. Bunun yanı sıra tedaviye yönelik başka işlemler için de manyetik özelliğe sahip kapsül, robot, ilaç taşıma sistemleri vb. araçlar geliştirilmektedir. $\mathrm{Bu}$ araçların yönlendirilmesi de bahsedilen sistemler aracılı̆̆ıyla temassız bir şekilde gerçekleştirilebilmektedir. Bu çalışmada temassız yönlendirmeyi sağlayan manyetik kateter navigasyon sistemleri hakkında bilgi verilmektedir.

Anahtar Kelimeler: Elektromanyetik sistemler, manyetik kateter, temassız yönlendirme sistemleri, kateter, manyetik navigasyon sistemler

\section{Abstract}

In the last 10 years, research has started on systems that will minimize the complications that may occur in procedures, such as endoscopy, colonoscopy, bronchoscopy, which are conventionally performed manually by the doctor and 
robotically during biopsy and diagnostic procedures. The most important feature of these systems is that the catheter has a magnetic character, and can be guided contactless via an electromagnetic systems. In addition, tools such as capsules, robots, and drug delivery systems with magnetic properties are being developed for other treatment approaches. In this study, the review of electromagnetic catheter navigation systems that provide contactless guidance has been provided.

Keywords: Electromagnetic systems, magnetic catheter, contactless guidance systems, catheter, magnetic navigation system

1. Giriş
Cerrahi operasyonlar, komplikasyon oluşturma

ihtimalinin bulunduğu, hem hasta hem doktor için zorlu bir süreçtir [1]. Bu süreci iki taraf için de kolaylaştıracak ve olası riskleri en aza indirerek operasyonun başarısını artıracak prosedürler ve uygulayıcı sistemler üzerine çalışmalar yapılmaktadır. Minimal invaziv cerrahi, tanı koyma veya tedavi işlemlerini daha küçük kesilerden yapmaya dayalı, genel ameliyat mantığına alternatif olarak geliştirilmiş bir yöntemdir. Hekimler hastalık teşhisi ve/veya tedavisi için biyopsi, oklüzyon tedavisi, bölgeye direkt ilaç tedavisi gibi müdahaleler için kateter kullanmaktadırlar [2]. Kateterler, gastrointestinal sistem [3], kardiyovasküler sistem [4], solunum sistemi [5] gibi önemli bölgelerde kullanılır. Kateterle vücut içerisinden hedef bölgeye ulaşarak gövdedeki damarlara müdahale etmek mümkündür. Geleneksel kateterler içi boş, esneyebilen malzemeden olup, 1ş1k, kamera, boş kısımdan geçen tüp veya telden oluşabilmektedirler [6][7][8]. Uygulama tipine göre kateterin çap1 ve uzunluğu da değişmektedir [9]. Geleneksel kateterler ile yapılan girişimlerde işlem sırasında ya da sonrasında enfeksiyon, kanama, bölgedeki dokuya zarar verme gibi komplikasyonlar oluşabilmektedir [10][11][12][13]. Bu gibi komplikasyonların önlenmesi için cerrahın el kabiliyetinden bağımsız olarak kateterlerin kontrollü yönlendirilmesini sağlayacak sistemlerin geliştirilmesi üzerine çalışılmaktadır [14]. Hekimlerin bir arayüz aracılığıyla uzaktan kontrol edebildiği sistemler geliştirilmiştir. $\mathrm{Bu}$ sistemlerde elektromanyetik düzenekler kateter stebilizasyonu ve uygulanabilirlik, hassasiyet sebebiyle akustik, optik, akışkan, elektrik alan gibi diğer uzaktan yönlendirme yöntemlerine göre daha çok tercih edilmektedir [15][16][17]. Elektromanyetik sistemlerde manyetik alan kaynağ 1 olarak sabit mıknatıslar ya da manyetik sargılar kullanılmaktadır. $\mathrm{Bu}$ sistemlerin bütünü "Elektromanyetik Aktüatörler (EMA)" olarak adlandırılır. EMA sistemleri çalışma uzayından, elektromanyetik sargılardan, kontrolcü ve görüntü geri besleme sisteminden oluşmaktadır. Çalışma uzayında bulunan manyetik bir cisme etkiyen kuvvet, bobinler üzerinden geçen elektrik akımının manyetik kuvvete dönüştürülmesi ile oluşmaktadır. Manyetik nesne, gradyan bazlı ya da tork bazlı olarak manipüle edilmektedir. Gradyan bazlı manipülasyonda nesnenin hareket ettirilme işlemi gerçekleşirken, tork bazlı manipülasyon işleminde nesnenin istenilen yöne döndürülmesi gerçekleştirilmektedir [18]. Görüntüleme, kamera, mikroskop, bilgisayarlı tomografi (BT), ultrasonografi (US), floroskopi, manyetik rezonans görüntülüme (MRG) [19] gibi yöntemlerle gerçekleştirilir. Manuel olarak yapılan cerrahi operasyonlarda meydana gelebilecek komplikasyonların oranının azaltılması üzerine çalışmalar yapılmaktadır [20]. $\mathrm{Bu}$ durum da birçok işlemde kullanılan kateter teknolojilerinin uzaktan kontrollü olarak yönlendirilmesini sağlayan elektromanyetik aktüatörler ve manyetik kateterlere olan ilginin artmasına sebep olmuştur[21][22].

\section{Manyetik Kateterler}

Manyetik kateterler, geleneksel kateterlerin sınırlamalarının üstesinden gelmek için manyetik bileşenin belirli mesafelerde konumlanmasıyla üretilirler. $\mathrm{Bu}$ şekilde harici bir EMA kullanılarak kateterin vücut içerisindeki konumunu ve yönünü kontrol etmek mümkündür [23]. Manyetik kateterler, elastik/hiperelastik ve biyouyumlu olan malzemelerden üretilmektedir [24]. Kateterlerin ucunda manyetik özellikte parça/parçalar bulunmaktadır (Şekil 1).

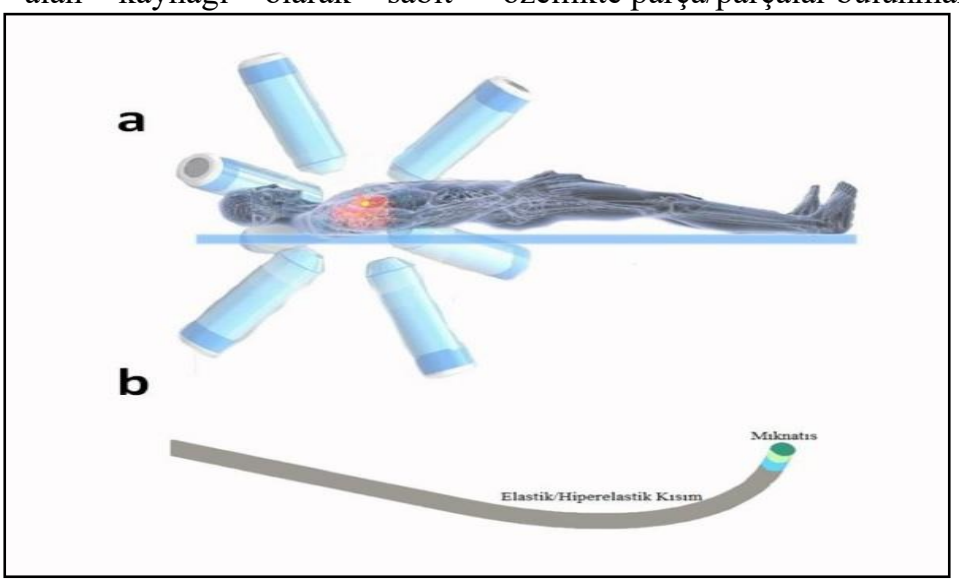

Şekil 1. a. Elektromanyetik Sistem Kateter Etkileşiminin Gösterimi b. Manyetik Elastik/Hiperelastik Kateter 
Damarların ve organların karmaşık üç boyutlu şekilleri, sistemin navigasyon yeteneğinin hassas olmasını gerektirmektedir. Kateter bazlı operasyonlarda bu hassasiyette müdahale etmek amaciyla, son on yılda hem manuel hem de robotik olarak idare edilebilir sistemler

\begin{tabular}{|c|c|c|}
\hline & Geleneksel Kateterler & Manyetik Kateterler \\
\hline Esneklik & $\begin{array}{l}\text { Sınırlı Hareket ve Esneklik Aralığı } \\
\text { sağlayabilmektedir. }\end{array}$ & $\begin{array}{c}\text { Miknatıslara etkiyen manyetik kuvvet ve tork } \\
\text { etkisiyle esnekliği artar. }\end{array}$ \\
\hline $\begin{array}{c}\text { Karmaşık } \\
\text { Anatomiye } \\
\text { Erişebilirlik }\end{array}$ & Hekimin el becerisine göre değişmektedir. & $\begin{array}{l}\text { Uzaktan yönlendirilebilirliği sayesinde kompleks } \\
\text { geometrilere daha rahat erişim sağlanır. }\end{array}$ \\
\hline Kateter Stabilitesi & Hekimin el becerisine göre değişmektedir. & $\begin{array}{l}\text { Manyetik navigasyon cihazı sayesinde daha stabil bir } \\
\text { duruş sergilemektedir. }\end{array}$ \\
\hline Hasta Güvenliği & $\begin{array}{l}\text { Kateterle yapılan işlemlerde hekimin el } \\
\text { becerisine göre dokuların tahribatı ya da } \\
\text { komplikasyonlar gerçekleşebilmektedir. }\end{array}$ & $\begin{array}{l}\text { Kateter, manyetik navigasyon cihaziyla daha } \\
\text { kontrollü olarak hareket ettirilebilmektedir. }\end{array}$ \\
\hline Hekim Güvenliği & $\begin{array}{l}\text { Hekim, doğrudan hastanın yanında } \\
\text { bulunması gerekmektedir. Bulaşıcı } \\
\text { hastalıklarda risk altında bulunmaktadır. }\end{array}$ & $\begin{array}{l}\text { Hekim ayrı bir kontrol odasından uzaktan kontrol } \\
\text { sağlayabilmektedir. }\end{array}$ \\
\hline Hastaya Erişim & $\begin{array}{l}\text { Uzman hekimlerim doğrudan hasta ile } \\
\text { teması gerekmektedir. }\end{array}$ & $\begin{array}{l}\text { Başka bir bölgedeki uzman hekim tarafindan hastaya } \\
\text { erişim sağlanabilmektedir. }\end{array}$ \\
\hline İşlem Süresi & $\begin{array}{l}\text { Operasyon süresi hekime göre } \\
\text { değişmektedir. }\end{array}$ & $\begin{array}{l}\text { Operasyon süreleri yapılacak işlem ve hedef bölgeye } \\
\text { göre standartlaşmaktadır fakat manuel sisteme göre } \\
\text { daha yavaştır. }\end{array}$ \\
\hline
\end{tabular}

ortaya çıkmıştır [25]. Geleneksel kateterlere alternatif olarak sensör tabanlı, kapasitif tip sensör vb kateter türleri de araştırılmıştır [26]. Tablo 1'de geleneksel ve manyetik kateterlerin kıyaslaması yapılmıştır.

Tablo 1. Geleneksel Kateter ve Manyetik Kateterlerin Karşılaştırılması[46][47][48]

Elektromanyetik (EM) paletli kateterler, üç boyutlu ultrason (3B-US) görüntüleme cihazını ve prostatta gerçek zamanlı yüksek doz hızlı (HDR) brakiterapi tedavi sistemini sağlamak için yeni bir tedavi planlama sistemini birleştiren platforma entegre edilmiştir. Bu tedavi planlama sistemi, üç EM sensörünün tamamından konturlamaya olanak tanıyan aerodinamik bir ortama sürekli konum ve açısal bilgiler göndermektedir [27]. Nguyen ve arkadaşları, otonom kateterizasyonda özellikle tromboz tedavisi için intravasküler terapötik yaklaşım olarak, son zamanlarda harici bir elektromanyetik aktüatör sistemi tarafından tahrik edilen robotik kateterleri araştırmışlardır. $\mathrm{Bu}$ ekip, tromboz tedavisi için bir intravasküler terapötik yaklaşım olarak karmaşık geometriye sahip olan kalp damarlarında elektromanyetik aktüatör tarafından yönlendirilen kateter kontrolünde EMA sistemi için 3 boyutlu pozunu tanımlayan bir yöntem önermişlerdir [28].

Operasyon türlerine göre tasarlanmış ve bu kısımlara uygulanan özel işlemlere göre üretilmiş kateterler bulunmaktadır. Kateter kullanımın sıkça duyulduğu kanser tedavisi için radyoaktif parçaların yerleştirilmesi brakiterapi [29], solunum yolları hastalıkları tanı ve tedavisi için bronkoskopi [30][31], yemek borusu-yutak, böbrek, mide-bağırsak (gastrointestinal) kısımlarında endoskopi [32], kardiyovasküler işlemler kardiyak kateterizasyon [33] kateterleri bulunmaktadır. Bahsedilen işlemler için son zamanlarda geleneksel kateterlerin yerine manyetik kateterlere yönlenilmeye başlanmıştır. $\mathrm{Bu}$ işlemlerde hassasiyet ve uygulama önemlidir. Örneğin, yüksek doz oranlı brakiterapinin doğru uygulanması, kateterlerinin konumunun ve şeklinin doğru tanımlanmasına bağlıdır. Brakiterapi uygulamalarında bu amaçla transrektal ultrason (TRUS) ve MRG görüntüleme kullanılmaktadır [19]. TRUS görüntüleri üzerinde manuel kateter tanımlaması, kalsifikasyonlar ve distal gölgeleme artefaktları nedeniyle zaman alıc1, subjektif ve operatöre bağlı olabilmektedir. Bu duruma çözüm amaçlı olarak, Bharat ve arkadaşları, dokuyu taklit eden bir fantom içine yerleştirilen kateterlerin konumunu ve şeklini haritalamak için elektromanyetik (EM) izleme teknolojisini kullanmışlardır [34]. 
Kalp ve damar hastalıklarına kateter ile müdahale işlemlerinde, elektromanyetik navigasyon sistemi (ENS) aortik ark kanülasyonunda in vitro performansını değerlendirme amaçlı üretilmektedir. Aortik ark ve torakoabdominal aort anevrizmasinı temsil eden silikon fantomların yeniden yapılandırılmış çok kesitli bilgisayarlı tomografi görüntülerinin, bir kılavuz telin ucundaki sensörler ile izlenerek 3 boyutlu görselleştirilmesi sağlanabilmektedir. ENS'de, manyetik alan oluşturmak için bir elektromanyetik aktüatör, fantomun diş çerçevesi üzerine sabitlenmiş, sistemin doğruluğunu sağlamak için uzamsal bir işaret olarak işlev gören 6 serbestlik dereceli referans noktas1, ekran monitörlü bir iş istasyonu, izlenebilen uçlu problar ve tezgah üstü çalışmalar için tasarlanmış uçta konum sensörüne sahip özel yapım, $50 \mathrm{~cm}$ uzunluğunda esnek bir tel bulunmaktadır [35]. Bu kateter, aort anevrizması harici başka hastalıkların tedavisinde de kullanılmaktadır. Beyin uygulamalarında ise hidrosefali hastalarında ventriküler kateter şant arızası, şant revizyonunun en yaygın nedenidir. Küçük ventrikül veya anormal ventrikül anatomisi olan hastalarda optimal ventriküler kateter yerleşimi aşırı derecede zor olabilmektedir. Küçük çocuklarda ve özellikle kafa boyutu küçük olan prematüre bebeklerde ventriküler kateterin tatmin edici bir şekilde konumlandırılması zor olabilmektedir. Elektromanyetik aktüatör teknolojisine sahip navigasyon, bu açıdan çekici ve yenilikçi bir tedavi seçeneği olarak görülmektedir. Hermann ve arkadaşları, ventriküler kateter şant arızası için pediyatrik hastalarda elektromanyetik navigasyon cihazı ve kateter yönlendirmesi ile işlem yapmışlardır[36].

SuperDimension Navigasyon Sistemine ait kavisli ve takip edilebilir sensörlü bir kateter, 5 serbestlik derecesine sahip bir elektromanyetik navigasyon sistemi ile hastalarda bronkoskopi işleminde, in vivo olarak denenmiştir [37][38]. Bu teknolojinin sadece akciğerlerde değil, kulak, burun, boğaz gibi organlarda da kullanılabileceğine kanaat getirilmiştir. Elektromanyetik navigasyon bronkoskopi (ENB), geleneksel tanı yöntemlerinden daha düşük komplikasyon oranına sahip soliter pulmoner lezyonların teşhisine yardımcı olabilmektedir. İnoperabl hastalarda ve transtorasik biyopsi sonrası komplikasyon riskini artıracak komorbiditeleri olanlarda ENB, yaklaşık \%3'lük düşük pnömotoraks oranları ile daha önce bulunmayan bir alternatif sunmaktadır. $\mathrm{Bu}$ nedenle elektromanyetik navigasyonlu bronkoskopi, zor periferik akciğer lezyonlarının teşhisinde manuel operasyona göre daha başarılıdır [39].

Kateterler, kardiyovasküler hastalıklarda oklüzyon tedavisi harici, kardiyak aritmilerde hastaların tedavisinde ablasyon işlemi amaçlı da kullanılmaktadır. Bauernfind ve arkadaşları, ablasyon prosedürlerini Siemens Axiom Artis (Siemens, Erlangen, Almanya) floroskopi sistemi içeren, Stereotaxis Niobe II (Stereotaxis, Inc., St Louis, MO, ABD) kullanarak gerçekleştirmişlerdir. Ventriküler taşıkardi ablasyonunda, manyetik navigasyon kılavuzlu kateterin manevra kabiliyetini zor pozisyonlarda bile koruduğu, manuel prosedüre göre daha başarılı olduğunu bu çalışma ile gösterilmiştir [40]. Başka bir çalışmada ise intravasküler sistem için 3 boyutlu kateter yönlendirmesini amaçlayan bir elektromanyetik sistem kullanarak intravasküler sistemde üç miknatıs uçlu kateterin yerleştirilmesi ve yönlendirilmesi için 8 adet elektromıknatısın olduğu elektromanyetik navigasyon sistemi kullanılmıştır. Kateterdeki mıknatıs sayısının artmasının kateter eğilmesindeki ve manevra kabiliyetindeki etkisi incelenmiştir. Miknatıs sayısı arttırılması ve mıknatıslar arası mesafe optimizasyonu ile kateter kontrolünde elektromanyetik sistemlerde kullanılabilmektedir [41]. Başka bir çalışmada, sol atriyumda atriyal fibrilasyon ablasyonu için MRG ile çalıştırılan yönlendirilebilir bir kateterin tasarım optimizasyonu Liu ve arkadaşları tarafindan sunulmaktadır. Polimer tüp üzerine inşa edilen kateterin manyetik bileşenleri, elektromanyetik sargılarla oluşturulmuştur. Sargılardan geçen akım değeri kontrol edilerek kateter istenilen yere yönlendirilebilmiştir [42][21].

Endovasküler sistemlerde elektromanyetik navigasyon ile kateter yönlendirme işlemlerinde fizibilite değerlendirme çalışmaları da yapılmaktadır. Lambert ve ekibi, endovasküler anevrizma onarımında kateterin navigasyonu için elektromanyetik navigasyon kullanmanın fizibilitesini değerlendirmek için iki farklı abdominal aort anevrizması fantomu için, sert bir plastik model ve yumuşak bir silikon model kullanmışlardır. Her fantom için prosedür öncesi, hastanın BT görüntülerinden elde edilen haritalandırma ile manyetik alanda intraoperatif simülasyon gerçekleştirmişlerdir. BT verilerinin ve elektromanyetik izleme verilerinin aorto iliak yapısındaki kateter pozisyonları ve bunların dönüm noktası olarak kullanılması mümkün olduğunu ayrıca bu navigasyon sisteminin, $\mathrm{X}$-1şınına maruz kalma süresinin, kontrast madde enjeksiyonu kullanımının azaltabileceği hususunda sonuçlara erişmişlerdir [43]. Uzaktan kateter yönlendirme üzerine çıkan çok sayıda bilimsel çalışma, elektromanyetik aktüatörlerin geliştirilmesi ve ticarileştirilmesi üzerine yoğunlaşılmasına sebebiyet vermektedir. Bu sistemlerin gelişimi, işlem hassasiyeti, hastada işlem yapılacak çalışma uzayına erişilebilirlik, hastaya erişilebilirlik, görüntüleme yöntemini ile koordinasyonu, sistem ebatları ve maliyeti gibi tasarım parametreleri düşünülerek yapılmaktadır [44][45].

Kateter Navigasyonu için Üreti Imiş Elektromanyetik Aktüatörler

Kateter navigasyon sistemleri ilk olarak kardiyak operasyonlar için robotik sistemler olarak geliştirilmiştir. $\mathrm{Bu}$ sistemlerden en eskisi Sensei [49][50], kateterin kardiyovasküler operasyonlarda 3 boyut içinde lokalizasyonunu sağlamak için 3B elektroanatomik atriyum haritalama (EAM) teknolojileriyle entegrasyonu için üretilmiştir. Bu teknolojinin geliştirilmesiyle ortaya çıkan bir diğer ürün Magellan sistemi (Hansen Medical, Inc.) ise, klinik uygulamalarda stent greftleme ve anevrizma onarımı dahil farklı endovasküler prosedürler için kullanılmaktadır. Ancak, bu sistem kuvvet algılama ve dokunsal geri bildirim sağlamaz ve navigasyon 
yalnızca floroskopi görüntüleme kullanılarak iki boyutlu olarak elde edilmektedir [51]. Magellan Robotik Sistemi, robotik kateterlerin ve kılavuz tellerin robotik kontrolünü sağlayan iş istasyonu, yatak başı askısı, robotik kateter manipülatörü (RKM) ve robotik tel manipülatörü (RTM) dahil olmak üzere dört ana bileşenden oluşur. Sistemin periferik vaskülatürdeki anatomik hedeflere olan navigasyonu kolaylaştırması ve ardından terapötik cihazların manuel olarak yerleştirilmesi için bir kanal sağlaması amaçlanmıştır. Bu sistem hekimin prosedürleri radyasyon kaynağından uzakta, iş istasyonu başında gerçekleştirmesine olanak tanımaktadır ve robotik yardımlı endovasküler prosedürler sırasında radyasyon maruziyetini yatak başı kontrole kıyasla \%90'dan fazla azalttığ1 gösterilmiştir [52]. Robotik navigasyon sistemleri üç boyutlu haritalama ve kateter stabilizasyonunu sağlasa da yönlendirilen kateter çaplarının büyük olması nedeniyle sınırlı bölgelere erişimi, manyetik navigasyon sistemlerine göre dezavantaj sağlamaktadır [53].

Manyetik navigasyon sistemlerinin en belirgin avantajlarından biri kateterlerin hassas olarak kateter stabilizasyonunu sağlamasıdır [53]. Bu sistemlerden en çok bilineni Niobe, Stereotaxis ${ }^{\circledR}$ uzaktan manyetik navigasyon sistemi, kateter stabilitesini artırabilecek ablasyona yeni bir yaklaşım sağlamaktadır. Kateterin uzaktan kontrolü, operatörün radyasyona maruz kalmasını önlemektedir. Hastanın her iki tarafına yerleştirilen büyük kalıcı mıknatıslardan oluşan Stereotaxis sistemi, kateter ucunu manuel veya otomatik olarak uzaktan yönlendirmek için kullanılmaktadır [54]. Bir diğer manyetik navigasyon sistemi olan Genesis,
Niobe sisteminin geliştirilmiş bir versiyonudur. Mıknatısların boyutu daha küçük ve daha hafiftir. Genesis Sistemi, Niobe Sistemi'nden yaklaşı olarak 90 $\mathrm{kg}$ daha hafiftir, klinik ekibi için daha hızlı yanıt alma ve daha rahat hasta erişimi sağlar. Miknatıslar hasta etrafında hareket edecek şekilde tasarlanmıştır [55][56]. Kateter Kontrolü ve Görüntüleme Sistemi'nde ise (CGCI, Magnetecs), dördü yarı küresel bir düzende, kalan dört miknatıs ise simetrik olarak alt kısımda olmak üzere hasta yatağının üst düzlemine yerleştirilen sekiz elektromıknatıstan oluşan bir manyetik odadan oluşmaktadır. Elektromıknatıslar 3B çalışma alanı etrafında sabitlenmiştir. Dönme veya translasyon hareketi yoktur. Sistemin tamam1, floroskopi, intrakardiyak ekokardiyografi vb. dahil olmak üzere kardiyak haritalama ve navigasyon ekipmanı ile entegre şekilde master-slave olarak kontrol edilmektedir [57][58]. Aegon Phocus manyetik navigasyon sistemi (Aegon Scientific, İsviçre) ise, hastanın ilgili çalışma alanının etrafına yerleştirilmiş yedi adet eş elektromıknatıstan oluşmaktadır. Bu sistem anjiyografi sistemi ile birlikte kullanılmakta; hekime, uzaktan temassız kontrol sağlamaktadır [59]. Aegon Phocus kardiyovasküler sistemlerde kardiyak aritmi tedavisi için üretilmiştir [60]. Kateterin uzaktan navigasyonunun gerçekleştirilmesini sağlayan cihazların bir kısmı laboratuvar ürünü olarak kullanılırken, bir kısmı ise ticari olarak kullanılmaktadır. Derlemede bahsedilen sistemler ticari olarak kullanılan sistemlerdir ve Tablo 2 'de bu sistemler hakkında literatüre dayalı genel bir karşılaştırılma yapılmıştır.

Tablo 2. Manyetik Kateter Yönlendirme Sistemleri Değerlendirme Tablosu

\begin{tabular}{|c|c|c|c|c|}
\hline $\begin{array}{c}\text { Tasarım } \\
\text { Kriterleri }\end{array}$ & Niobe & Genesis & Magnetecs & Aegon Phocus \\
\hline $\begin{array}{l}\text { Hedef Bölge } \\
\text { ve Tedavi }\end{array}$ & $\begin{array}{l}\text { Kalp- } \\
\text { Kardiyak Aritmi }\end{array}$ & Kardiyak Aritmi & $\begin{array}{c}\text { Kalp içi ekokardiyografi dahil olmak } \\
\text { üzere kardiyak haritalama }\end{array}$ & $\begin{array}{l}\text { Kardiyak aritmileri } \\
\text { tedavisi için kateter } \\
\text { yönlendirme }\end{array}$ \\
\hline Yapılan İşlem & $\begin{array}{c}\text { Kateter } \\
\text { ablasyonunun } \\
\text { uzaktan kontrolü için } \\
\text { bir kateter ilerletme } \\
\text { sistemi }\end{array}$ & $\begin{array}{l}\text { Kateter ablasyonunun } \\
\text { uzaktan kontrolü için bir } \\
\text { kateter ilerletme sistem }\end{array}$ & Kateter ablasyonu & Kateter ablasyonu \\
\hline $\begin{array}{l}\text { Miknatıslar } \\
\text { Sabit ya da } \\
\text { Hareketli }\end{array}$ & Sabit & $\begin{array}{l}\text { Mıknatısların arkaya } \\
\text { döndürülen mekanik } \\
\text { motorlar tarafindan } \\
\text { tutulduğu ve pivot etrafında } \\
\text { sallandığı sistem }\end{array}$ & $\begin{array}{c}\text { Miknatıslar, } 3 \text { boyutlu çalışma } \\
\text { alanının etrafina sabitlenmiştir, yani } \\
\text { diğer manyetik çalıştırma } \\
\text { sistemlerinde olduğu gibi } \\
\text { mıknatısların dönme veya öteleme } \\
\text { hareketi yoktur. }\end{array}$ & Sabit \\
\hline $\begin{array}{c}\text { Miknatıs } \\
\text { Saytst ve } \\
\text { Konumlama }\end{array}$ & $\begin{array}{l}\text { Hastanın yatağının } \\
\text { her iki tarafına da } \\
\text { konumlanmış sabit } \\
\text { mıknatıslar }\end{array}$ & $\begin{array}{l}\text { Hasta yatağının her iki } \\
\text { tarafına daimi mıknatıslar }\end{array}$ & $\begin{array}{l}\text { 4'ü üst düzleme 4'ü alt düzleme, üst } \\
\text { ve alt düzlem simetrik olacak şekilde } \\
\text { yerleştirilen elektromıknatıslar }\end{array}$ & $\begin{array}{l}\text { Sistem hastanın } \\
\text { gövdesinin etrafına } \\
\text { yerleştirilmiş } 7 \text { adet } \\
\text { elektromıknatıs }\end{array}$ \\
\hline $\begin{array}{c}\text { Hastaya } \\
\text { Erişilebilirlik }\end{array}$ & Normal & Normal & Sinırlı & Sinırlı \\
\hline $\begin{array}{l}\text { Görüntüleme } \\
\quad \text { Sistemi }\end{array}$ & $\begin{array}{l}\text { Tek Düzlem } \\
\text { Floroskopi Sistemi }\end{array}$ & $\begin{array}{l}\text { C-arm görüntüleme, } \\
\text { master-slave sistem }\end{array}$ & $\begin{array}{l}\text { Floroskopi, } \\
\text { master-slave }\end{array}$ & Anjiyografi sistemi \\
\hline Sinirlamalar & $\begin{array}{l}\text { Mıknatısların yavaş } \\
\text { dönüş hızı ve sınırlı } \\
\text { tepki süresi vardır. }\end{array}$ & $\begin{array}{l}\text { Niobe Sistemi'ne göre daha } \\
\text { verimlidir. Ancak sabit } \\
\text { mıknatısların mekanik } \\
\text { ataletlerinden kaynaklı } \\
\text { olarak tepki süresi yavaştır. }\end{array}$ & $\begin{array}{l}\text { Mıknatısların sabit pozisyonda } \\
\text { (dönme veya translasyon hareketi } \\
\text { yoktur) olmasıdır ve bu hastaya } \\
\text { sınırlı erişim verir. }\end{array}$ & $\begin{array}{l}\text { Hastanın üst gövdesinin } \\
\text { üstünde } 7 \text { adet } \\
\text { elektromıknatıs, } \\
\text { operatörün hastaya } \\
\text { ulaşımını kısıtlamasıdır. }\end{array}$ \\
\hline
\end{tabular}




\section{Manyetik Navigasyon Sistemleri}
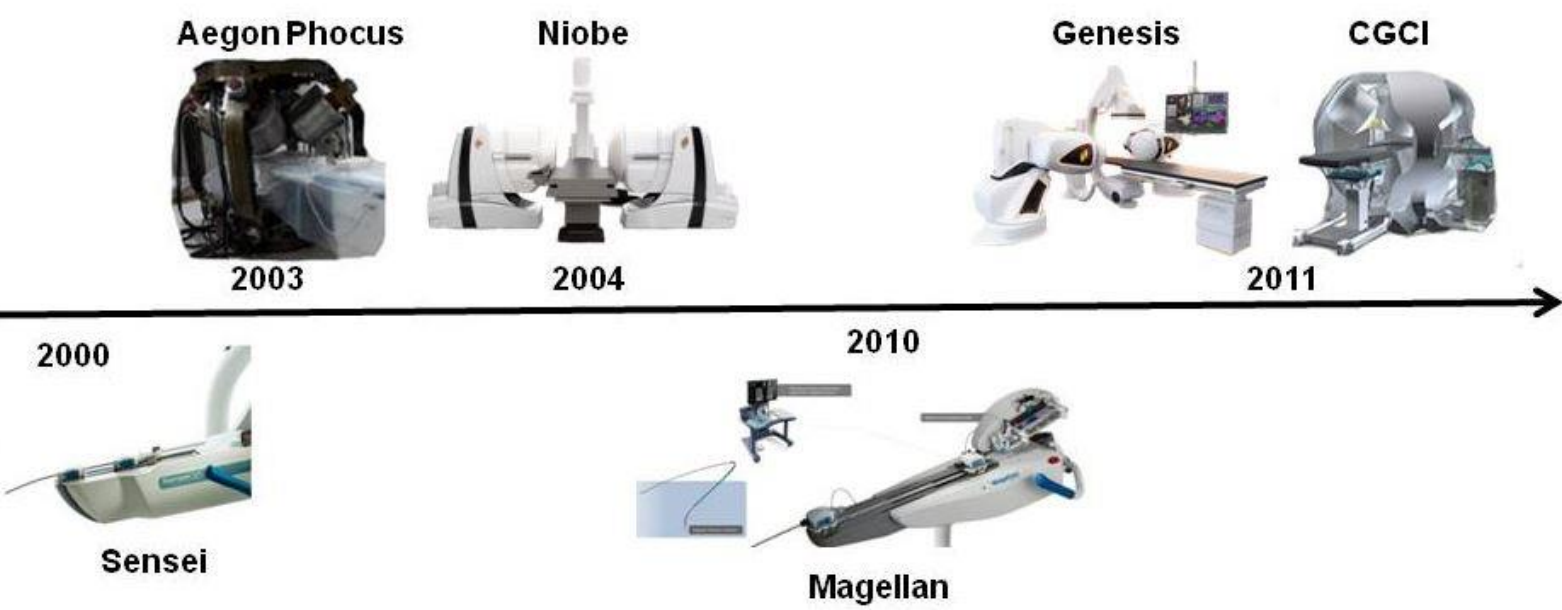

Robotik Navigasyon Sistemleri

Şekil 2. Ürünleşmiş Robotik ve Manyetik Navigasyon Sistemlerinin Zaman Çizelgesinde Gösterimi

Piyasadaki bu ticari ürün olarak bahsedilen robotik ve manyetik/ elektromanyetik aktüatörlerin zaman çizelgesinde gösterimi Şekil 2'de verilmiştir.

\section{Tartışma}

Manyetik özellikli kateterlerin uzaktan ve kontrollü olarak yönlendirilmesi ile, yapılacak operasyonun daha hassas gerçekleştirildiği, manuel ve robotik operasyonlara göre daha az komplikasyon oluşturduğu gözlemlenmektedir. $\mathrm{Bu}$ da vücut içinde karmaşık geometrili ve ulaşılması zor bölgelere ulaşım için umut vadeden bir çözüm olarak görülmektedir. Ayrıca uzaktan kontrolle birlikte hastanın komplikasyonları azaltılırken, iyileşme süreci de hızlanacak ve sağlık sistemi bünyesinde yapılan harcamalar da azaltılabilecektir. Fakat bu sistemlerin yatırım maliyeti diğerlerine göre fazladır. Manyetik navigasyon sistemlerinin, manuel ve robotik sistemlere göre operasyon sürelerinin uzun olması, boyutlarının büyük olması ve yer kaplaması, sistemin taşınamaması gibi dezavantajları da bulunmaktadır. Sistemlerin kullanımı hekimler açısından daha kolaydır; fakat hekimlerin özel olarak bu sistemlerin kullanımı hakkında ekstra bir eğitim alması gerekmektedir. Hekimlerin paradigma değişimlerine karşı dirençli davranması bu sürecin uzamasına sebep olabilmektedir.

\section{Sonuc}

Bu sistemler sayesinde, uzaktan yönlendirme sayesinde bu konuda uzman olarak yetişmiş hekimlerin, uzman hekim bulunmayan bölgelerdeki vakalarla ilgilenmesi de söz konusu olabilmektedir. Gelecekte bu tarz manyetik navigasyon sistemlerinin kateter harici mikrorobot, nanorobot, hedeflenmiş ilaç taşıma gibi farklı operasyonel araçlar için de uygulanabileceği ve elektromanyetik aktüatörlerin daha hızlı, küçük ve kolay kullanımlı sistemlere olanak verecek şekilde geliştirilebileceği düşünülmektedir.

\section{Teșekkür ve Bilgilendirme}

$\mathrm{Bu}$ çalışma, Türkiye Bilimsel ve Teknik Araştırma Kurumu (TÜBİTAK) tarafından 118 E769 numaralı proje ile desteklenmiştir.

\section{Referanslar}

1.Skervin, A, Levy, B, Management of common surgical complications, Surgery (United Kingdom), 2020, 38, 128-132.

2. Ali, A, Plettenburg, D.H, Breedveld, P, Steerable Catheters in Cardiology: Classifying Steerability and Assessing Future Challenges, IEEE Transactions on Biomedical Engineering, 2016, 63, 679-693.

3. Speir, E.J, Newsome, J.M, Bercu, Z.L, Miller, M.J, Martin, J.G, Correlation of CT Angiography and 99mTechnetium-Labeled Red Blood Cell Scintigraphy to Catheter Angiography for Lower Gastrointestinal Bleeding: A Single-Institution Experience, Journal of Vascular and Interventional Radiology, 2019, 30, 1725-1732.e7.

4. Yarmohammadi, H, Shenoy, C, Cardiovascular magnetic resonance imaging before catheter ablation for atrial fibrillation: Much more than left atrial and pulmonary venous anatomy, International Journal of Cardiology, 2015, 179, 461-464.

5. Hautmann, H, Schneider, A, Pinkau, T, Peltz, F, Feussner, H, Electromagnetic catheter navigation during bronchoscopy: Validation of a novel method by conventional fluoroscopy, CHEST Journal, 2005,128, 382-387.

6. Michalski, D, Tabor, Z, Zieliński, B, Determining the shift of a bronchoscope catheter from the analysis of a video sequence of a bronchoscope video camera, Biocybernetics and Biomedical Engineering, 2017, 37, 630-636.

7. Abbott, J.E, Heinemann, A, Badalament, R, Davalos, J.G, A clever technique for placement of a urinary catheter over a wire, Urology. Аппиа, 2015, 7, 367-370.

8. Deng, R. Di et al., A novel double-balloon catheter for percutaneous balloon pulmonary valvuloplasty under echocardiographic guidance only, Journal of Cardiology, 2020. 
9. Mt. Laurel, NJ. Care and Management of Patients with Urinary Catheters: A Clinical Resource Guide, The Wound, Ostomy, and Continence Nurses Society, 2016.

10. Igawa, Y, Wyndaele, J.J, Nishizawa, O, Catheterization: Possible complications and their prevention and treatment, International Journal of Urology, 2008, 15, 481-485.

11. Kornbau, C, Lee, K, Hughes, G, Firstenberg, M, Central line complications, International Journal of Critical Illness and Injury Science, 2015, 5, 170.

12. Biffi, R. et al., Best choice of central venous insertion site for the prevention of catheter-related complications in adult patients who need cancer therapy: A randomized trial, Annals of Oncology, 2009, 20, 935-940.

13. Levy, I., Gralnek, I.M, Complications of diagnostic colonoscopy, upper endoscopy, and enteroscopy, Best Practice \& Research: Clinical Gastroenterology Special Issues, 2016, 30, 705-718.

14. Sheng, K. X. et al., Comparative efficacy and safety of lock solutions for the prevention of catheter-related complications including infectious and bleeding events in adult haemodialysis patients: a systematic review and network meta-analysis, Clinical Microbiology and Infection, 2020, 26, 545-552

15. Zhang, Z, Wang, X, Liu, J, Dai, C, Sun, Y, Robotic Micromanipulation: Fundamentals and Applications, Annua Reviews in Control Autonomic Systems, 2019, 2, 181-203 (2019).

16. Shauer, A. et al., Clinical research: Remote magnetic navigation vs Manually controlled catheter ablation of right ventricular outflow tract arrhythmias: A retrospective study, Europace, 2018, 20, ii28ii32.

17. Kataria, V, Berte, B, Vandekerckhove, Y, Tavernier, R, Duytschaever, M, Remote Magnetic versus Manual Navigation for Radiofrequency Ablation of Paroxysmal Atrial Fibrillation: LongTerm, Controlled Data in a Large Cohort, BioMed Research International, 2017.

18. Cao, Q. et al., Recent advances in manipulation of micro- and nanoobjects with magnetic fields at small scales, Material Horizons, 2020 7, 638-666.

19. de Arcos, J. et al,. Prospective Clinical Implementation of a Nove Magnetic Resonance Tracking Device for Real-Time Brachytherapy Catheter Positioning, International Journal of Radiation Oncology, Biology, Physics, 2017, 99, 618-626.

20. Alemzadeh, H, Raman, J, Leveson, N, Kalbarczyk, Z, Iyer, R.K Adverse events in robotic surgery: A retrospective study of 14 years of the data, PLoS One, 2016, 11, 1-20.

21. Muller, L, Saeed, M, Wilson, M.W, Hetts, S.W, Remote control catheter navigation: Options for guidance under MRI, Journal of Cardiovascular Magnetic Resonance, 2012, 14, 1-9.

22. Rafii-Tari, H, Payne, C.J, Yang, G.Z, Current and emerging robotassisted endovascular catheterization technologies: A review, Annals of Biomedical Engineering, 2014, 42, 697-715.

23. Kim, N, Lee, S, Lee, W, Jang, G, Development of a magnetic catheter with rotating multi-magnets to achieve unclogging motions with enhanced steering capability, AIP Advances, 2018, 8

24. Spilezewski, K.L, Anderson, J. M, Schaap, R.N, Solomon, D.D, In vivo biocompatibility of catheter materials, Biomaterials, 1988, 9 , 253-256

25. Ali, A, Plettenburg, D.H, Breedveld, P, Steerable Catheters in Cardiology: Classifying Steerability and Assessing Future Challenges, IEEE Transactions on Biomedical Engineering, 2016, 63, 679-693.

26. Ahmadi, M, Zhang, Y, Rajamani, R, Timm, G, Sezen, A.S, A SuperCapacitive Pressure Sensor for a Urethral Catheter, Annual International Conferences of the IEEE Engineering in Medicine and Biology Society, 2018, 3453-3455.

27. Hu, X, Chen, A, Luo, Y, Zhang, C, Zhang, E, Steerable catheters for minimally invasive surgery: a review and future directions, Computer Assisted Surgery, 2018, 23, 21-41.

28. Aagaard, P, Natale, A, Di Biase, L, Robotic navigation for catheter ablation: Benefits and challenges, Expert Review of Medical Device, $2015,12,457-469$

29. Ullah, W. et al., Comparison of Robotic and Manual Persistent AF Ablation Using Catheter Contact Force Sensing: An Internationa Multicenter Registry Study, PACE - Pacing and Clinical Electrophysiolog, 2014, 37, 1427-1435.

30. Beaulieu, L. et al., Real-time electromagnetic tracking-based treatment platform for high-dose-rate prostate brachytherapy:
Clinical workflows and end-to-end validation, Brachytherapy, 2018, $17,103-110$

31. Nguyen, P. B. et al,. Real-time microrobot posture recognition via biplane X-ray imaging system for external electromagnetic actuation, International Journal of Computer Assisted Radiology and Surgery, 2018,13, 1843-1852.

32. Jaselskè, E, Adlienė, D, Rudžianskas, V, Urbonavičius, B.G, Inčiūra, A, In vivo dose verification method in catheter based high dose rate brachytherapy, Physica Medica, 2017, 44, 1-10.

33. Paul, S, Munavvar, M, Flexible bronchoscopy, Medical (United Kingdom), 2020, 48, 257-262.

34. Murgu, S.D, Robotic assisted-bronchoscopy: Technical tips and lessons learned from the initial experience with sampling peripheral lung lesions, BMC Pulmonary Medicine, 2019, 19, 1-8.

35. Miyagaki, H. et al., Performance comparison of peripherally inserted central venous catheters in gastrointestinal surgery: A randomized controlled trial, Clinical Nutrition, 2012, 31, 48-52.

36. Lee, S.E, Lin, F.Y, Lu, Y, Chang, H.J, Min, J.K, Rationale and design of the Coronary Computed Tomographic Angiography for Selective Cardiac Catheterization: Relation to Cardiovascular Outcomes, Cost Effectiveness and Quality of Life (CONSERVE) trial, American Heart Journal, 2017, 186, 48-55.

37. Bharat, S, et al., Electromagnetic tracking for catheter reconstruction in ultrasound-guided high-dose-rate brachytherapy of the prostate, Brachytherapy, 2014, 13, 640-650.

38. Cochennec, F, Riga, C, Hamady, M, Cheshire, N, Bicknell, C, Improved catheter navigation with $3 \mathrm{D}$ electromagnetic guidance, Journal of Endovascular Therapy, 2013, 20, 39-47.

9. Hermann, E.J, Capelle, H.H, Tschan, C.A, Krauss, J.K, Electromagnetic-guided neuronavigation for safe placement of intraventricular catheters in pediatric neurosurgery: Clinical article, Journal of Neurosurgery Pediatrics, 2012, 10, 327-333.

40. O’Donoghue, K. et al., Catheter position tracking system using planar magnetics and closed loop current control, IEEE Transactions on Magnetics, 2014, 50.

41. Jaeger, H.A. et al., Automated Catheter Navigation With Electromagnetic Image Guidance, IEEE Transactions on Biomedical Engineering, 2017, 64, 1972-1979.

42. Mukherjee, S, Chacey, M, Diagnostic Yield of Electromagnetic Navigation Bronchoscopy Using a Curved-tip Catheter to Aid in the Diagnosis of Pulmonary Lesions, Journal of Medical Devices, Transactions of the ASME, 2017, 24, 35-39.

43. Bauernfeind, T. et al, The magnetic navigation system allows safety and high efficacy for ablation of arrhythmias, Europace, 2011, 13, 1015-1021.

44. Le, V.N.T, Nguyen, N.H, Alameh, K, Weerasooriya, R, Pratten, P, Accurate modeling and positioning of a magnetically controlled catheter tip, Medical Physics, 2016, 43, 650-663.

45. Liu, T, Poirot, N.L, Greigarn, T, Çavuşoğlu, M.C, Design of a magnetic resonance imaging guided magnetically actuated steerable catheter, Journal of Medical Devices ASME, 2017, 11

46. De Lambert, A, et al. Electromagnetic tracking for registration and navigation in endovascular aneurysm repair: A phantom study, European Journal of Vascular and Endovascular Surgery, 2012, 43 684-689.

47. Fitan, E, Messine, F, Nogarède, B, The electromagnetic actuato design problem: A general and rational approach, IEEE Transactions on Magnetics, 2004, 40, 1579-1590.

48. Antico, M. et al., Ultrasound guidance in minimally invasive robotic procedures, Medical Image Analysis, 2019, 54, 149-167.

49. Di Biase, L. et al., Ablation of atrial fibrillation utilizing robotic catheter navigation in comparison to manual navigation and ablation: Single-center experience, Journal of Cardiovascular Electrophysiology, 2009, 20, 1328-1335.

50. Hlivák, P. et al., Robotic navigation in catheter ablation for paroxysmal atrial fibrillation: Midterm efficacy and predictors of postablation arrhythmia recurrences, Journal of Cardiovascular Electrophysiology, 2011, 22, 534-540.

51. Rafii-Tari, H, et al., Reducing contact forces in the arch and supraaortic vessels using the Magellan robot, Journal of Vascular Surgery, 2016, 64, 1422-1432.

52. De Ruiter, Q.M.B, Moll, F.L, Van Herwaarden, J.A, Current state in tracking and robotic navigation systems for application in endovascular aortic aneurysm repair, Journal of Vascular Surgery, $2015,61,256-264$ 
53. Schmidt, B. et al., Remote navigation systems in electrophysiology, Europace, 2008, 10 Suppl 3.

54. Carpi, F, Pappone, C, Stereotaxis Niobe ${ }^{\circledR}$ magnetic navigation system for endocardial catheter ablation and gastrointestinal capsule endoscopy, Expert Review of Medical Devices, 2009, 6, 487-498.

55. Newswire, E.A, New Option for Catheter Guidance Control and Imaging : Interview with Jose L . Merino , MD , PhD, 2011, 11, 1-2.

56. Gianni, C, Natale, A, Horton, R.P, Remote Catheter Navigation Systems, Catheter Ablation of Cardiac Arrhythmias Elsevier Inc., 2019, doi:10.1016/B978-0-323-52992-1.00008-9

57. Moya, À. et al., Innovations in Heart Rhythm Disturbances: Cardiac Electrophysiology, Arrhythmias and Cardiac Pacing, Revista Española de Cardiología (English Edition), 2013, (English Ed. 66, 116-123.

58. Gang, E.S. et al., Dynamically shaped magnetic fields: Initial anima validation of a new remote electrophysiology catheter guidance and control system, Circulation: Arrhythmia and Electrophysiology, 2011, 4, 770-777.

59. Phocus, A, Electromagnetic Steering of Interventional Instruments, 2015, 41, 1-22.

60. Liu, J. et al., Design and Fabrication of a Catheter Magnetic Navigation System for Cardiac Arrhythmias, IEEE Transaction Applied Superconductivity, 2016, 26.

http://edergi.cbu.edu.tr/ojs/index.php/cbusbed isimli yazarın CBU-SBED başlıklı eseri bu Creative Commons Alıntı-Gayriticari4.0 Uluslararası Lisansı ile lisanslanmıştır. 